\title{
Teachers' Perception of Their Work Environment: Evidence from the Primary and Secondary Schools of Bangladesh
}

\author{
Muhammad Rehan Masoom (10) \\ School of Business \& Economics, United International University, Dhaka 1212, Bangladesh \\ Correspondence should be addressed to Muhammad Rehan Masoom; rehan_1611@yahoo.com
}

Received 18 October 2021; Accepted 1 November 2021; Published 24 November 2021

Academic Editor: Ehsan Namaziandost

Copyright (c) 2021 Muhammad Rehan Masoom. This is an open access article distributed under the Creative Commons Attribution License, which permits unrestricted use, distribution, and reproduction in any medium, provided the original work is properly cited.

\begin{abstract}
The work environment includes conducive aspects such as (1) organizational encouragement, (2) supervisory encouragement, and (3) workgroup support, as well as toxic conditions like (4) teaching impediments and (5) workload pressure; the objective of the research is which of the factors and what are the elements of those factors teachers perceive as constituting the conducive and toxic environment. The research also outlines the effects of years of experience and the level of teaching on the specified factors. The study used a quantitative-based cross-sectional survey to analyze teachers' perceptions of their work environment. A questionnaire comprised some background information, and 34 close-ended questions were used to elicit the responses. About 368 (230 males and 138 females) teachers participated in the survey. Structural equation models were constructed, where the five mentioned factors were part of two second-order formative constructs. Independent sample $t$-test was estimated to outline gender-wise and teaching level-wise (primary and secondary) variation, whereas Pearson correlation coefficients were calculated to check whether the experience was correlated with any of the perceived factors of the work environment. It is found that workgroup encouragement, particularly having good relations with the principal, is the most important factor in the conducive environment of the school. The physical facilities were the least, whereas promoting positive behavior by avoiding conflict and ensuring fairness was the most important aspect of organizational encouragement. Teaching impediments were mostly shaped by how often teachers require dealing with disruptive and violent pupils. Teachers perceived too many after-school meetings, unreasonable deadlines, and office staffs' inspections enhance their workload pressure. The more a teacher became experienced, the more he or she positively perceived the conducive environment of the school. The findings can serve as a guide for educational policymakers and school administrators to identify which factors in the school environment need urgent attention and modification.
\end{abstract}

\section{Introduction}

The work environment of teachers is vital; after all, the working environment of teachers is the learning condition of students, and the unproblematic environment in which to teach is also the comfortable environment in which to learn [1]. High satisfaction and low intention to leave the teaching profession are high among teachers in schools with favourable working conditions, regardless of student demographics and socioeconomic background of the teachers [2]. Schools' organizational characteristics have been the subject of a growing body of research (cf. [3]). Despite growing recognition of the critical nature of working conditions, researchers have only recently begun to understand how various aspects of the workplace affect teachers' ability to teach effectively, their sense of self-efficacy, their satisfaction with their role and assignment, and their willingness to remain in their school and profession [4]. Teacher demographics, qualifications, school organizational traits, school resources, and student body characteristics are all factors that influence teacher attrition [5]. Teaching conditions are more important than previously thought in predicting teacher attrition [5]. Working conditions, notably administrative assistance, school amenities, and class size, are far more significant to teachers than remuneration and student demographics [6]. Working conditions, in addition 
to salary and incentives, have a significant impact on teachers' career intentions [7, 8]. Another crucial factor influencing teachers' career choices is school administration, specifically the quality of a school's leadership [7, 8].

The success of any school is depending on seven pivotal issues, "teacher selection, teacher dismissal, evaluation policy, enrolment policy, textbook selection, curriculum content, and curriculum design" [9]. However, interpersonal, academic, socioeconomic, political and administrative relationships are all part of educational institutions. In primary and secondary schools, a conglomeration of intellectuals and well-informed individuals hailing from different sociocultural, ethnic, and religious backgrounds come together to pursue a single goal providing education [10]. Like all other organizations, a school is a workplace for teachers, and a specific working environment, as well as the overall arrangement of these specific circumstances, can influence their perspective. Some features of the work environment are essential, but their effects on well-being will vary as to their level increases [11]. These features include (1) opportunity for control; (2) opportunity for skill use; (3) externally generated goals; (4) variety, (5) environmental clarity; (6) availability of money; (7) physical security, (8) opportunity for interpersonal contact; (9) valued social position. While all of them are important for psychological well-being in moderation, some, like workload, are thought to be damaging to well-being at very high levels. Some other variables, including money and social status, are unlikely to harm well-being even if their level is high. Teachers' selfefficacy is influenced by collective efficacy, school environment, and mastery experiences [12], whereas perceived organizational support can enhance educators' self-esteem by reducing occupational stress [13].

A recent research indicates that excessive workload, bias based on social identity perception, discrimination and favouritism, not receiving help from upper management, feeling unvalued, and financial issues were among the reasons instructors quit school management [14]. Besides, unhappiness and anxiety, feelings of depression, failure and inadequacy, mental exhaustion and depersonalization, anxiety, dilemma, tension, feeling worthless, anxiety, hurt, and apathy were among the emotional states generated by these factors [14]. Recently, an approach was developed to measure the employee's perceptions of an acceptable workplace; such things as effort and commitment to the organization, as well as what they expect in return, like payment, respect, or promotion, were factors in an employee's perception of a healthy workplace [15]. It is believed that a psychological contract exists between employees and employers. If an employee believes their employer has failed to uphold this contract by, for example, not promoting someone based on effort, they will experience stronger negative emotions that can negatively affect their physical and mental health in the long term. When the psychological contract is viewed as fair, psychological well-being is likely to improve. The work environment is characterized in this approach as a set of beliefs held by the employee about how the organization will respond to their job activities. Where employees perceive some factors in the work environment as unsatisfying, then such an environment may be construed as being toxic. Hence, for an environment to be perceived as satisfying (conducive), the Person (p)-Environment (E) relationship must be equivalent, such as $E$ should fulfil the requirement of $\mathrm{P}[16]$.

The work environment includes the sum of the interrelationships that exist among the employees and the employers; it reflects the conducive aspects like organizational and supervisory encouragement, workgroup support as well as toxic conditions like insufficient resources, organizational impediments, and work pressure [17]. The basic question the present research deals with is which of the factors do teachers consider as constituting the conducive and the toxic environment of the schools. It may also be of interest to inquire into which of these factors in work environments exert more influence on job commitment. Further, the teachers' skills may develop to where they outgrow their role, or their priorities may shift because of non-work commitments; likewise, the nature of the work environment or the rewards that a school can offer may change over the years [18]. The correspondence between the teacher and the school environment may not be perfect, perhaps because the teacher chose the wrong career or the school administration chose the wrong person; even a good correspondence can deteriorate over time [19]. Hence, it is worthy to outline the relationships between the factors and the year of experiences by the teachers.

A variety of factors can affect the physical and psychological well-being of teachers in the work environment. The present research focuses on understanding and explaining how teachers perceive their work environment. The objective here is to gain a better understanding of those aspects of work environments that are believed to have a significant impact on teaching. There has been no reliable, valid method for adequately assessing the teachers' percept of their work environment dimensions. Promoting effective teaching for all students, especially those from low-income families, cannot be achieved by merely offering financial rewards or through compelling teachers to reassign [20]. Good teachers will come and remain, and their pupils will learn if the school is known for being a helpful and productive environment [21]. Besides, the work environment is related to school policies. The administrators of schools need to understand the school's environment to enhance the job commitment of the teachers and be able to develop policies that are consistent with the academic curriculum. Therefore, an empirical probing to answer these questions will serve as a guide to educational policymakers and school administrators to identify which factors in the school environment need urgent attention and modification.

\section{Conceptual Framework}

The work environment is the environment in which people work; from the physical environment, such as heat and equipment, job-specific characteristics such as workload and task complexity, broader organizational features such as culture and history, and to the extra-organizational factors such as local labour market conditions, industry sector, and 
work-home relationships, all are part of the work environment [22]. While the influence of physical workplace conditions, such as the presence of a toxic substance, is often quite apparent, it is less direct how social environments affect teachers' perception [23]. Conducive work environments provide teachers with pleasurable experiences and assist them in actualizing their goals; toxic work environments are responsible for painful experiences that deactualize their behaviour [24]. Since educational institutions, such as primary and secondary schools, have a unique work environment that differs in a lot of ways from other manufacturing or service-based organizations, we may need to broaden our understanding by investigating what could be toxic or conducive to teachers [22]. While organizational, supervisory, and workgroup encouragement may contribute in teacher retention, teaching impediments, and unreasonable workload pressure may contribute in teacher attrition.

2.1. Organizational Encouragement. The working environment of teachers is extremely important to them and, ultimately, to their students; teachers are more satisfied and intend to stay longer in schools with a positive work environment, regardless of the student demographic characteristics of the school [25]. Clean and well-maintained facilities and access to new instructional technology are not the most important aspects of the work environment for teachers [26]. The physical surroundings, such as safety and comfort, as well as economic variables like compensation and job security, were all important aspects of a teacher's employment; it also incorporates assignment structures such as workload and supervision, as well as cultural and social variables such as organizational culture strength and coworker and student qualities [12]. Unsurprisingly, those who want to improve student learning by improving the teacher's workplace tend to focus on easily manipulative elements like remuneration, class size, and job security [20]. However, many aspects of the teachers' workplace are still outside the purview of dispute settlement, laws and regulations, and administrative rule-making [27]. These are the elements of the social context of schooling that have a significant impact on efforts to improve schools and children's school outcomes [28]. Apart from the factors like emotions, and subjective well-being [29], the perception regarding how much they are valued in the workplace as well as home, and how much they are maintaining the balance between personal-professional lives are related to the administrative encouragement of the school [30].

\subsection{Supervisory Encouragement. Teachers who experienced} greater levels of satisfaction and academic progress were those who worked in schools where principal leadership, collegial relationships, and school culture were resilient [25]. The principal and teachers work together to create, enact, and promote a positive school culture; the principal can expect the school to be a safe and orderly environment for teaching and learning, but unless the teachers play a role, it will be controlled by regulations rather than norms [25]. A principal facilitates teachers' collegial contacts by encouraging them to collaborate, ensuring that they have time to do so, and mediating their relationships. However, unless the school culture encourages all students to share their knowledge, expert teachers' best practices may never spread beyond their classrooms [31]. While a principal may have the most formal authority in a school, without the daily support of teachers, that authority falls far short of what is required to truly transform a school from good to great [32]. A good principal understands the distinction between what she can achieve through decisive leadership and what she can only develop by fostering positive working relationships [33]. Such principals understand that it is the social context of teachers' work that allows them to have the most success with students. Because colleagues play an important role in teachers' development, it is critical to assemble a staff of teachers who share core values and is committed to improving their practice, both individually and collectively [33].

The quality management system depends on data utilization, leadership, and discussion formats, all of which contribute to reasonably intimate and network of relationships among the colleagues [34]. The capacity of schools to improve teaching can be increased by guiding individual teachers and using systematic and meaningful evaluations. Teachers in their mid-career years who participated in the Teacher Evaluation System, which is peer-evaluated, improved their students' performance, as measured by student test score gains, both during the year of the evaluation and in the years following [35]. Even when a school actively involves teachers in collaborative learning and development, some teachers may be unable or unwilling to improve. Due to the critical nature of teachers' work, their performance should be evaluated regularly; those who lack the skills or attitudes to achieve success with students should be encouraged [36]. Therefore, effective principals maintain order in the classroom, respond to teachers' concerns, and provide instructional leadership by ensuring that teachers receive regular and relevant feedback on their teaching [37].

\subsection{Workgroup Encouragement. Teachers' job satisfaction} and career aspirations are mostly determined by social factors, such as the school's culture, the principal's leadership, and connections among co-workers [38]. Improving these social conditions involves building relational trust between teachers and school leaders and engaging teachers in coconstructing the social context of their work [39]. The school environment includes the social relations of "teachers with students, teachers with other teachers, teachers with parents and with their school principal" [40]. These daily relationships require a high level of trust, and they show how important social exchanges are to a school's ability to improve [40]. Hence, it is no surprise then that teachers' work with students is heavily influenced by their relationships with other adults, such as their colleagues at school [41]. Teachers who have supportive collegial contacts can learn from one another, handle problems together, and keep one another accountable [42]. 
Teachers who work in schools with more supportive principals and colleagues are more likely to stay [43]. It appears likely that such schools perform better than others at attracting and retaining effective teachers [43]. A prospective teacher who is serious about becoming a successful teacher, especially one who is personally motivated to serve lowincome, minority students, will most likely want to collaborate with others who share her goals and expectations [44]. A school with a strong professional culture will retain that teacher [41]. Therefore, students would benefit from attending a school known for attracting and retaining likeminded teachers [45]. Teachers who collaborate and learn from one another regularly have a positive work environment. When working with more effective colleagues, elementary school teachers can raise student test scores [46]; hence, collegial relationships can help teachers. Positive collegial interactions are likely to support student learning. Therefore, schools with stronger work cultures appear to be more favourable to teachers and students working together to achieve their goals, which is dependent on how much teachers trust and respect one another, how comfortable they are addressing issues, and how committed they are to helping students learn [47].

2.4. Teaching Impediments. The efficacy of teachers is determined by the students they educate; many teachers opt to work with groups of high-poverty, high-minority pupils because they believe they can contribute to the public good by teaching these students [48]. At the same time, some teachers may avoid dealing with the same groups of students for a variety of reasons, including personal discomfort or reservations about their ability to teach them effectively [48]. Teachers may find it difficult to differentiate between problems created by pupils and problems produced by a dysfunctional work environment when deciding whether to stay at their current school or transfer to another [49]. For example, when the underlying problem is a terrible school culture or teachers who feel accountable primarily for what happens in their classroom, they may accuse students of chaotic or dangerous situations in the classrooms [49]. Leaving teaching professions is influenced more by student demographics than by compensation; Instead of leaving their schools, teachers chose to leave their pupils [50]. Low teacher retention rate is common in schools attended by minority and low-income students [8].

Teachers' daily experiences in school are shaped in part by students; however, they are far from the only factor influencing their attitudes. Sometimes, the restroom facilities are considered as the level of service quality by the educational institutions [51]. While effective coordination at the school management team level helps reduce the amount of school violence [52], a lack of relational trust among actors and components in school management hampered community participation, which in turn hampered the overall progress of the community [53]. If schools are to attract and retain the best teachers to work with the most vulnerable students, they cannot be places of deprivation, disorder, and isolation, as neither teachers nor students will thrive in such environments
[54]. When schools are unable to provide teachers with minimally acceptable staff support, teachers develop symptomatic responsiveness to their work environment [55]. Teachers who work in schools with extremely poor working circumstances are three times more likely to plan to transfer than teachers who work in schools with ordinary working conditions [25]. High turnover rates of teachers disrupt efforts to build meaningful collegial connections, improve instructional capacity, and create a strong organizational culture.

2.5. Workload Pressure. Qualitative and quantitative workload, control or discretion over the way employees perform tasks, task repetition, and role ambiguity are major aspects of the work environment [56]. Jobs that require demanding schedules but little direct influence over their content are the most detrimental to overall health [57]. The negative impact of high demands is mitigated by high control; employment with this combination is not harmful; instead, it allows the employee to learn and grow [58]. High job expectations are not damaging; it depends on the level of control available [58]. Regardless of the abstract job attributes, actual workplace events that do not always cause distinct emotional and behavioural responses affect what employees feel about their job [59]. Undeniably, several physical aspects of the classroom, such as heat, noise, and lighting, have been shown to have an indirect and direct effect on several psychological processes in teaching [60]. However, not all characteristics of the work environment are equally essential or relevant for teachers' perceptions of their workload.

Everything that is a burden on the teacher is also a burden on the student [54]. A pleasant working environment makes a job easier or comfortable. Less work or no work hours, less responsibility, or minimal supervision are all ways this can be achieved [61]. It is unquestionably critical to have safe facilities, proper resources, and adequate preparation time for instructors if they are to succeed with their pupils, particularly low-income and high-minority students who solely rely on the school for their education [62]. They must also be able to rely on their colleagues, their administration, and the school's organizational culture to help them succeed. However, the conditions of their job that were most important to them were not the ones that made their jobs easy, but the ones that supported their ability to do their jobs effectively [63]. While not all teachers' interests are always aligned with what is best for their students, a positive school environment has been shown to positively influence student learning. Early career teachers have been increasingly leaving schools in high-minority, high-poverty areas to work in schools in higher-income areas or fields other than education [64]. Both large-scale quantitative and small-scale qualitative studies document this pattern of teachers moving from low-income to high-income schools [5]. The schools that needed the most effective teachers, therefore, had the most trouble attracting and keeping them [5]. Rather than the pupils they educate, teachers who quit high-poverty, high-minority schools despise the dysfunctional environments in which they work [7]. 


\section{Methods}

3.1. Design and Instrument. The research used a quantitative-based cross-sectional design to analyze teachers' perceptions of their work environment. A questionnaire comprised some background information, such as gender, age, year of experience, and level of teaching, and 34 closeended questions were used to elicit the responses. These 34 items were developed by following the guidance of the National Education Union (NEU) of the United Kingdom. NEU works for the well-being of the teacher to ensure an appropriate education system. The items of the factors associated with the conducive and toxic elements of the environment were quantified by a five-point Likert scale, where 1 indicated "Strongly disagree" and 5 indicated "Strongly agree". No item was required to be reverse coded.

3.2. Sampling. The study tested the developed model on a homogeneous purposive sample of school teachers. About fifty undergrad students from a particular institution were requested to go back to their schools in Dhaka and collect data from their teachers. Data collection was voluntary for those undergrad students; about 368 teachers from 36 distinct schools and colleges participated in the survey.

3.3. Procedure. A structural equation model was constructed in IBM SPSS Amos graphics (version 24) by following the conceptual model. All five factors were part of two secondorder formative constructs in the recursive model. By estimating the "confirmatory factor analysis" (CFA), the standardized regression weights $(\beta)$ of the corresponding factors associated with either conducive or toxic variables were calculated. The validity of the model was checked by the most commonly used fitness indices, such as absolute fit with root mean square of error approximation (RMSEA) and goodness of fit index (GFI), incremental fit with comparative fit index (CFI), and parsimonious fit with minimum discrepancy/ degrees of freedom (CMIN/DF). These indices were also estimated for the conducive and toxic variables separately. Internal consistency of the factors was estimated by Cronbach's alpha and composite reliability (CR); the discriminant validity was measured by the average variance extracted (AVE). Principal component analysis (PCA) was used to reduce the dimensions to check whether the perceptions of the five elements varied by gender and years of experience. Independent sample $t$-test was estimated to outline genderwise and teaching level-wise variation, whereas Pearson correlation coefficients were calculated to check whether the experience was correlated with any of the perceived factors of the work environment. The $t$-test and correlation coefficient were estimated by IBM SPSS Statistics (version 23).

\section{Results}

4.1. Participants. A total of 368 teachers, 230 (62.5\%) males and $138(37.5 \%)$ females, participated in the survey. About 137 (112 males and 25 females) of them were teaching at the primary level, about 196 were teaching at the secondary level, and the rest of the 35 teachers taught both primary level and secondary level students. The youngest teacher aged 24.5 and the oldest teacher aged 44 , and their mean age was 31.68; their teaching experiences varied from 6 months to 20 years, with a mean year of experience of $7.68( \pm 5.62)$ years (see Table 1 for more results).

4.2. Estimates. Three factors, organizational encouragement, supervisory encouragement, and workgroup encouragement, to address the conducive environment reached the construct validity; estimated indices, such as CMIN/DF (2.278) [65], CFI, GFI, AGFI (>.9) [66], and RMSEA (<.059) [67], indicated the satisfactory fit of the model while compared to conventionally acceptable ranges.

The estimated weight $(\beta)$ for organizational encouragement to the conducive environment as a second-order formative construct was .749. As a unidimensional factor, it accounted for $39.84 \%$ of total variance explained. In the second-order formative construct of the variable, on average, $26.10 \%$ of the variations in teacher's perception regarding organizational encouragement were explained by the five specified items. The internal consistency, composite reliability (0.632), and Cronbach's alpha (0.631) of the factor were moderately acceptable. Items like promoting positive behaviour (0.624), helping to maintain work-life balance (0.555), and acceptable working hours (0.504) were the most influential to address organizational encouragement.

The estimated weight $(\beta)$ for supervisory encouragement to the conducive environment as a second-order formative construct was 0.843 . As a unidimensional factor, it accounted for $53.87 \%$ of total variance explained. In the second-order formative construct of the variable, on average, $42.0 \%$ of the variations in teachers' perception regarding supervisory encouragement were explained by the four specified items. The internal consistency, such as composite reliability (0.737), and Cronbach's alpha (0.708) of the factor were acceptable. All the items, changes accompanied by support and training (0.786), full staff consultation when any significant changes were proposed (0.727), effective leadership (0.516), and self-training (0.518) were found influential.

The estimated weight $(\beta)$ for workgroup encouragement to the conducive environment as a second-order formative construct was 1.017 . The values rarely suppress 1 ; however, values can exceed 1 in case of multicollinearity, which does not regard the model as faulty [68]. As a unidimensional factor, it accounted for $45.38 \%$ of total variance explained. In the second-order formative construct of the variable, on average, $32.30 \%$ of the variations in teachers' perception regarding supervisory encouragement were explained by the six specified items. The internal consistency, such as composite reliability (0.740), and Cronbach's alpha (0.758) of the factor were acceptable. All the items, skills well-used (0.558), feel valued in role (0.542), opportunities to express ideas and perspectives (0.528), encouraged to use skills and take initiatives (0.598), regular positive feedback (0.586), and good relationship with the principal (0.592) were found influential. 
Table 1: Participants.

\begin{tabular}{|c|c|c|c|}
\hline \multirow{2}{*}{ Level } & \multicolumn{2}{|c|}{ Gender } & \multirow{2}{*}{ Total } \\
\hline & Male & Female & \\
\hline \multirow{2}{*}{ Primary } & 112 & 25 & 137 \\
\hline & $30.4 \%$ & $6.8 \%$ & $37.2 \%$ \\
\hline \multirow{2}{*}{ Secondary } & 93 & 103 & 196 \\
\hline & $25.3 \%$ & $28.0 \%$ & $53.3 \%$ \\
\hline \multirow{2}{*}{ Primary and secondary } & 25 & 10 & 35 \\
\hline & $6.8 \%$ & $2.7 \%$ & $9.5 \%$ \\
\hline \multirow{2}{*}{ Total } & 230 & 138 & 368 \\
\hline & $62.5 \%$ & $37.5 \%$ & $100.0 \%$ \\
\hline
\end{tabular}

Two factors teaching impediments and workload pressure to address the toxic environment reached the construct validity; estimated indices, such as CMIN/DF (2.84) [65], CFI, GFI, AGFI (>.9) [66], and RMSEA (0.071) [67], indicated satisfactory fit of the model while compared to conventionally acceptable ranges.

The estimated weight $(\beta)$ for teaching impediments to the toxic environment as a second-order formative construct was 0.848. As a unidimensional factor, it accounted for $45.85 \%$ of total variance explained. In the second-order formative construct of the variable, on average, $32.2 \%$ of the variations in teachers' perception regarding teaching impediments were explained by the six specified items. The internal consistency, such as composite reliability $(0.720)$, and Cronbach's alpha (0.710) of the factor were acceptable. Items like dealing with disruptive pupils (0.825) and dealing with violent pupils $(0.745)$ were found influential.

The estimated weight $(\beta)$ for workload pressure to the toxic environment as a second-order formative construct was 0.674. As a unidimensional factor, it accounted for $38.52 \%$ of total variance explained. In the second-order formative construct of the variable, on average, $26.4 \%$ of the variations in teachers' perception regarding workload pressure were explained by the six specified items. The internal consistency, such as composite reliability (0.681), and Cronbach's alpha (0.677) of the factor were acceptable. Items like too many after-school meetings (0.583), unreasonable deadlines and time pressures (0.530), and office inspections on work (0.539) were found influential.

For more results, see Table 2.

Finally, the work environment as the second-order formative construct with two factors, positive (conducive/ encouragement) and negative (toxic/challenges), was found good (not satisfactory) by incremental fit indices (CFI, AGFI greater than 0.8 but less than 0.9) [30], while the parsimonious fit index (chisq/df $=2.434$ ) and root mean square error of approximation $(\mathrm{RMSE}=.062)$ indicated it a satisfactory fit.

Consider Figure 1 as the final model of the Work environment.

4.3. Variation by Gender, Teaching Level, and Year of Experience. Independent sample $t$-test results indicated that the perception of the five factors did not significantly differ by gender. However, comparing the level of teaching, considering 137 teachers teaching at the primary level and 196 teachers teaching at the secondary level, teachers' perceptions of their school environment varied. Compared with teachers teaching in primary level, the teachers teaching in secondary level perceived positively of the positive factors, such as organizational Encouragement $(t=-2.604 ; \mathrm{df}=331$; $p=0.010)$, supervisory encouragement $(t=-2.707 ; \mathrm{df}=331$; $p=0.007)$, and workgroup encouragement $(t=-3.209$; $\mathrm{df}=331 ; p=0.001)$. Teachers teaching at the secondary level felt less work pressure than the teachers teaching at the primary level $(t=-2.492 ; \mathrm{df}=331 ; p=0.013)$. However, perception of teaching Impediments did not vary $(t=1.602$; $\mathrm{df}=331 ; p=0.111)$ by the level of teaching. Teachers' perceptions varied by year of experience. It was found the more a teacher became experienced, the more he or she positively perceived organizational encouragement $(r=.226$; $p=.001)$, supervisory encouragement $(r=.203 ; p=0.001)$, and workgroup encouragement $(r=.231 ; p=0.001)$. However, perceived teaching impediments $(r=-.093$; $p=0.074)$ and workload pressure $(r=-.013 ; p=0.806) \mathrm{did}$ not significantly vary with years of experience.

\section{Discussion}

The full range and interdependence of the factors, from the physical and transactional features, such as salary, workload, and contractual responsibilities, to the social and transformative dimensions, such as relationships with co-workers and administrators, workplace culture, that define a teacher's workplace must be recognized in any meaningful analysis [69]. The basic question was: which of the factors do teachers of the primary and secondary schools consider as making them feel as though they work in a toxic or conducive environment. Having identified five factors within the work environment of the school, the study outlined which, among these factors, exert more influence or contribute more to the job commitment of teachers in schools. Results of the present research indicate that workgroup encouragement is the most important factor to maintain the conducive environment of the school. The workgroup encouragement was addressed by the perception of the teachers that they have a good relationship with the principal, encourage to use skills or initiatives to teach, have opportunities to express ideas or perspectives, regularly receive positive feedback and feel valued in his or her role. Supervisory encouragement 
TABLE 2: Estimated standardized regression weights of conducive and toxic variables in distinct SEMs.

\begin{tabular}{|c|c|c|c|}
\hline $\begin{array}{l}\text { Variables in } \\
\text { environment }\end{array}$ & Sr. & Factors and corresponding items & Estimate \\
\hline Conducive/positive & & Organizational encouragement ( $A V E=0.261 ; C R=0.632 ;$ Cronbach's alpha $=0.631)$ & 0.749 \\
\hline $\mathrm{CMIN} / \mathrm{DF}=20.28$ & OE1 & My physical working conditions are acceptable & 0.411 \\
\hline $\mathrm{CFI}=0.913$ & OE2 & My total working hours are acceptable & 0.504 \\
\hline $\mathrm{GFI}=0.933$ & OE3 & The balance between work and home life is about right & 0.555 \\
\hline $\mathrm{AGFI}=0.908$ & OE4 & The school values the time we put in at home & 0.427 \\
\hline $\mathrm{RMSE}=0.059$ & OE5 & $\begin{array}{l}\text { Management promotes positive behaviours at work to avoid conflict and ensure fairness in the } \\
\text { workplace }\end{array}$ & 0.624 \\
\hline \multirow{12}{*}{$\mathrm{SRMR}=0.056$} & & Supervisory encouragement $(A V E=0.420 ; C R=0.737 ;$ Cronbach's alpha $=0.708)$ & 0.843 \\
\hline & SE6 & Changes are accompanied by appropriate support and training, where necessary & 0.786 \\
\hline & SE7 & There is full staff consultation when any significant change is proposed & 0.727 \\
\hline & SE8 & The school benefits from effective leadership & 0.516 \\
\hline & SE9 & I receive appropriate training & 0.518 \\
\hline & & Workgroup encouragement $(A V E=0.323 ; C R=0.740 ;$ Cronbach's alpha $=0.758)$ & $1.017^{*}$ \\
\hline & WE10 & My skills are well-used & 0.558 \\
\hline & WE11 & I feel valued in my role & 0.542 \\
\hline & WE12 & I have opportunities to express my ideas and points of view & 0.528 \\
\hline & WE13 & I am encouraged to use my skills and initiative to do my work & 0.598 \\
\hline & WE14 & I regularly receive positive feedback on my work & 0.586 \\
\hline & WE15 & I have a good relationship with my principal & 0.592 \\
\hline Toxic/challenges & & Teaching impediments $(A V E=0.322 ; C R=0.720 ;$ Cronbach's alpha $=0.710)$ & 0.848 \\
\hline $\mathrm{CMIN} / \mathrm{DF}=20.84$ & TI16 & There are too few support staff in the school & 0.404 \\
\hline $\mathrm{CFI}=0.89$ & TI17 & Staff are afraid to complain in case they are "picked on" & 0.447 \\
\hline $\mathrm{GFI}=0.939$ & TI18 & I regularly have to deal with disruptive pupils & 0.825 \\
\hline $\mathrm{AGFI}=0.908$ & TI19 & I have to deal with violent pupils & 0.745 \\
\hline $\mathrm{RMSE}=0.071$ & TI20 & I am concerned about violence from aggressive parents & 0.396 \\
\hline \multirow[t]{8}{*}{$\mathrm{SRMR}=0.071$} & TI21 & Our rest facilities are shoddy and dispiriting & 0.420 \\
\hline & & Workload pressure $(A V E=0.264 ; C R=0.681 ;$ Cronbach's alpha $=0.677)$ & 0.674 \\
\hline & WP22 & There are too many after-school meetings & 0.583 \\
\hline & WP23 & Unreasonable deadlines and time pressures are often imposed on me & 0.530 \\
\hline & WP24 & Office staffs inspections cause me excessive pressure & 0.539 \\
\hline & WP25 & Lesson planning requirements are over-burdensome & 0.489 \\
\hline & WP26 & There is too much classroom observation & 0.499 \\
\hline & WP27 & I have to neglect some tasks because I have too much to do. & 0.430 \\
\hline
\end{tabular}

Note. ${ }^{*}$ Value greater than 1 indicates multicollinearity. The bold texts indicate that they are the weight of factor loadings.

accounted for 84.3 percent of the variances, particularly the importance of support and training, where necessary to deal with curriculum changing decisions (explaining $78.60 \%$ variance) as well as full staff consultation (explaining $72.70 \%$ variance). Organizational encouragement was found comparatively less important than supervisory or workgroup encouragement. The physical facilities were the least (explaining $41.10 \%$ variance) and promoting positive behaviour at work by avoiding conflict to ensure fairness was the most (explaining $62.40 \%$ variance) aspect or item to address organizational encouragement. The challenges of teaching, which were regarded as teaching impediments were shaped by how much a teacher requires dealing with disruptive pupils (explaining $82.50 \%$ variance) and violent pupils (explaining $74.50 \%$ variance) on regular basis. Aggressive parents (explaining $39.60 \%$ variance) and shoddy or dispiriting rest facilities (explaining $42.0 \%$ variance) were not found to the great concern for teaching impediments. Teachers perceived too many after-school meetings (explaining $58.30 \%$ variance), unreasonable deadlines (explaining
$53.0 \%$ variance), and office staffs' inspections (explaining $53.90 \%$ variance) were the aspects or items contributing to their workload pressure.

Previous studies report on some critical aspects; a significant element in the teachers' working environment is the principal's leadership $[7,8]$. According to a study of Portuguese principals, problems arising from the process of school clustering and the leader-centered style of school management have always been a source of concern for the dysfunctional educational system [70]. Principals and teachers work together to create a school climate that promotes order, engages parents, and encourages student learning [28]. Students benefit when their principal and teachers work together to ensure that prospective colleagues understand the demands of the job, are aware of the resources available to them and are aware of the expectations that others have for them [71]. Apart from the social relationships, some other factors of the school work environment have several potential effects on effective teaching. Teachers in the same school have widely varying levels of effectiveness [50]. Once teachers were hired, there was no 




FIGURE 1: Work environment recursive model (Amos output). Note. CMIN/DF $=2.434 ; \mathrm{CFI}=.811 ; \mathrm{GFI}=.867 ; \mathrm{AGFI}=.842 ; \mathrm{RMSE}=.062$; SRMR $=.0709$.

guarantee that they would remain effective [72]. Not only does the setting in which teachers work have a big impact on their capacity to offer effective education, but it also varies a lot from school to school and district to district [73]. For instance, in schools with large populations of low-income and minority students, teacher turnover is high because teachers are fleeing dysfunctional and unsupportive work environments [25].

The findings also suggest that teaching at the secondary level is more encouraging than teaching at the primary level. Teachers in the primary level feel the pressure of their workload more than the teachers teaching at the secondary level. Likewise, the more a teacher gathers teaching experiences, the more he or she finds the school environment encouraging his or her teaching. However, both the less experienced and more experienced teachers perceived the toxic elements of the school environment as almost equally challenging. Previously, it was found that less experienced teachers are less effective than their more experienced colleagues [74]. When an experienced teacher leaves a school, especially one that serves low-income, high-minority students, she will almost certainly be replaced by a first-year teacher who is far less successful [75]. Schools and students suffer when early career teachers leave high-need schools after two or three years, just as they have gained valuable teaching experience [76]. As a result, schools with high turnover find it difficult to build instructional capacity and ensure that all students have effective teachers in all classrooms [77]. When teaching staff turnover is high, it is difficult to formulate a policy and maintain coordinated educational programs across a school [78].

\section{Implications and Limitations}

Teaching and learning take place in a social context shaped by school culture, the principal's leadership, and their connections with their co-workers, and supported by school resources, or planning time, and some other physical facilities [47]. Religious, honest, disciplined, and clean and healthy school cultures all contribute to character development of the students [79]. Therefore, understanding the toxic and conducive elements of the work environment has several implications. First, teachers are the single most important factor affecting students' achievement at the school level, particularly for the poor students who typically have less learning supports elsewhere [80]; therefore, retaining good teachers ensures poor students to make progress in their academic ventures. Second, the apparent relationship between student demographics and teacher turnover is driven not by teachers' responses to their students, but by the conditions under which teachers teach and their students learn [6]; hence, knowing what transform a good working condition to great will enhance learning. Third, favourable working conditions predict academic growth in students, even when comparing schools serving demographically dissimilar student groups [8]; a diverse working environment teaches students how to contribute with their unique abilities and perspectives by studying and collaborating alongside people from a range of backgrounds and cultures. Fourth, since schools can attract and keep talented teachers by providing them with the circumstances and support they need to succeed with their students, regardless of their socioeconomic status [81], students avail an opportunity of more thorough understanding of the subject matter from the subject 
experts. Finally, teachers who are irresponsible or uncommitted to teaching can learn to be more responsible and committed to their jobs in a supportive work environment, which reinforces their self-actualizing traits.

These findings are relevant to both the decision-making process and on-the-ground practice. The traditional rigid school has been replaced by more complex and interdependent working relationships among teachers [82]. However, there has been a recent increase in the importance placed on student achievement in low-income, high-minority schools and thus a concomitant increase in the number of analysts and policymakers who concentrate solely on the needs of students. A range of working conditions matters to teachers; students in low-income, majority-minority schools are most likely to achieve quality skills if teachers are retained [44]. It has also been reported that the results of the United States School Climate Survey were more likely to be seen and used by school administrators than by teachers and other personnel [83]. Policymakers seeking to retain effective teachers and raise student performance, particularly in institutionally understaffed schools, should pay particular attention to the school context as experienced by teachers [45]. Policymakers should avoid mandating rigidity in schools and instead promote changes that foster creativity, adaptability, and collaboration among school personnel. The most essential decision an administrator makes when trying to fix failing schools is to hire and appoint principals who know how to work constructively with teachers to develop a school organization [84]. Besides, a good teacher may not remain good in every work context. Moving a teacher from a school with a strong, positive school culture to one with a weak or negative school culture may reduce her effectiveness, not because she becomes a less skilled teacher, but because she can no longer rely on a consistent code of behaviour or high expectations among her colleagues and students [85]. A strong, positive school culture that is consistently promoted by teachers and the principal can improve learning in every classroom throughout the school.

The study provided a thorough grasp of how to address the work environment in primary and secondary schools by considering both the positive and negative effects of work on employees' well-being. While clarifying precisely what has to be explained about teachers' perception is an important step forward in comprehending the links between the work environment and effective teaching, there are few limitations to this research. First, the study did not focus on any specific and diagnosable mental health conditions. For instance, depression or anxiety disorders, mood states related to motivation, such as fatigue or tiredness, other mood states, such as depression or boredom, and specific emotions, such as anger or resentment, are all part of well-being which is not included in the model. Each of these types of phenomena will certainly require a novel form of explanation, and the problem will determine which one will be the most useful that future study can focus on. Second, one strategy to improve understanding can be to consider the impact of various contexts on work and well-being. Individual features and personality traits of the teachers, as well as the specific conditions in that job or organization, are examples of such contexts. The study did not focus on the specific contexts, but considered only the general perceptions of the teachers. Third, since the effects are contingent on how the work is viewed, the study did not consider which particular aspects of work will influence the well-being of the teachers. The findings of the research can help to understand what kind of intervention we require for teachers in primary and secondary school contexts, but that may not be useful for tertiary-level teachers. Finally, there is still much to understand about the work environment in schools and the level of commitment of teachers. For instance, how workplace politics, rumour-mongering, mistrust, or alienation contribute to the work environment would help remove the toxic nature.

\section{Conclusion}

Teachers' perceptions of their working conditions are significant to understanding their workplace. Many research ventures have aimed to uncover the major features of the working environment. While there is evidence that links work environment and well-being, interest in the pleasant parts of work appears to have been overshadowed by analysing the work stressors. The influence of work stress on health has been studied empirically and theoretically for at least the last 30 years. Primarily the scholars focused on the presence of chronic emotional and interpersonal stressors in the work environment that leads to burnout. There are a series of stressors, such as workload and role ambiguity, present in the work environment that is associated with a series of strains, and a number of variables, such as coping, personality, and social support, moderate the strength of this relationship. When some characteristics of the workplace are seen unfavourably, it can have a detrimental impact on one's well-being. Where there is a lack of correspondence means that job commitment may be affected. The relationship between job demands, or workload, and well-being depends on the level of control, or freedom to make decisions the worker has over their job. However, as negative and stressful aspects of work dominate professional thinking about the workplace, a growing body of evidence suggests that work can be beneficial to both physical and psychological health.

Teachers' feelings, thoughts, and behaviours affect their perception of the environment. According to the findings of this study, workgroup encouragement is the most essential factor in maintaining a positive learning environment. The teachers' perceptions of having a good relationship with the principal, being encouraged to use skills or initiatives to teach, having opportunities to express ideas or perspectives, receiving positive feedback on a regular basis, and feeling valued in his or her role were addressed by the workgroup encouragement. While supervisory encouragement, particularly the need of assistance and training, was shown to be more important than supervisory or workgroup encouragement when dealing with curriculum changing decisions and complete staff consultation, organizational encouragement was found to be less important. The least important feature or item to address organizational encouragement 
was physical amenities, while the most important aspect or item was promoting positive behaviour at work through avoiding confrontation to maintain justice. The difficulties that teachers face, which are referred to as teaching impediments, are shaped by how frequently a teacher must deal with unruly and violent students. Teachers are unconcerned about aggressive parents or substandard or depressing rest facilities. Too many after-school meetings, arbitrary deadlines, and office staff inspections, according to teachers, are factors adding to their workload stress. However, we should remember that all organizations, even in the same industry and same line of operations or business, are not all the same in structure, culture, vision, mission, etc., while no individuals are of same character, attitudes, and personality; perception of work environment undoubtedly will vary from one teacher to another and from one level of teacher to another.

\section{Data Availability}

Primary data used in the research are available (https://doi. org/10.17632/bdptn474yv.1. https:/data.mendeley.com/ datasets/bdptn474yv/draft?a=da3b44e2-d403-45a2-933c-9e d2a11c7d53).

\section{Conflicts of Interest}

The author declares that there are no conflicts of interest regarding the publication of this study. No sensitive personal data used in this research.

\section{Acknowledgments}

The author would like to thank the surveyors.

\section{References}

[1] M. A. Haley, "Why teachers should organize," Journal of Education, vol. 60, no. 13, pp. 215-222, 1904.

[2] M. Charner-Laird, M. Ng, S. M. Johnson, M. A. Kraft, and J. P. Papay, "Gauging goodness of fit: teachers' responses to their instructional teams in high-poverty schools," American Journal of Education, vol. 123, no. 4, pp. 553-584, 2017.

[3] M. Connolly, D. H. Eddy-Spicer, C. James, and S. D. Kruse, The SAGE Handbook of School Organization, Sage, California, USA, 2018.

[4] S. J. Reaves and J. Allen, "Teacher perceptions of climate, motivation, and self-efficacy: is there really a connection," Journal of Education and Training Studies, vol. 6, no. 12, pp. 48-67, 2018.

[5] G. D. Borman and N. Maritza Dowling, "Teacher attrition and retention: a meta-analytic and narrative review of the research," Review of Educational Research, vol. 78, no. 3, pp. 367-409, 2008.

[6] E. Horng, "Teacher tradeoffs: disentangling teachers' preferences for working conditions and student demographics," American Educational Research Journal, vol. 46, no. 3, pp. 690-717, 2009.

[7] D. Boyd, P. Grossman, I. Marsha, L. Hamilton, S. Loeb, and W. James, "The influence of school administrators on teacher retention decisions," American Educational Research Journal, vol. 48, no. 2, pp. 303-333, 2011.
[8] H. F. Ladd, "Teachers' perceptions of their working conditions: how predictive of planned and actual teacher movement?" Educational Evaluation and Policy Analysis, vol. 33, no. 2, pp. 235-261, 2011.

[9] D. Zhao and L. Wang, "School governance structure and its impact on student performance: a comparative study between four provinces of China and the PISA2015 high-scored countries/economies," Best Evidence in Chinese Education, vol. 6, no. 2, pp. 825-843, 2020.

[10] O. S. Oludeyi, "A review of literature on work environment and work commitment: implication for future research in citadels of learning," Journal of Human Resource Managemnt, vol. 18, no. 2, pp. 32-46, 2015.

[11] P. Warr, Work, Unemployment, and Mental Health, Oxford University Press, Oxford, USA, 1987.

[12] C. Wilson, L. Marks Woolfson, and D. Kevin, "School environment and mastery experience as predictors of teachers' self-efficacy beliefs towards inclusive teaching," International Journal of Inclusive Education, vol. 24, no. 2, pp. 218-234, 2020.

[13] M. R. Masoom, "Educators' self-esteem: the effect of perceived occupational stress and the role of organizational support," International Journal of Educational Management, vol. 35, no. 5, pp. 1000-1015, 2021.

[14] E. Kazak, "The reasons of teachers to leave the school management voluntarily and their emotions based on these reasons: a phenomenological study," Eğitimde Nitel Araştırmalar Dergisi, vol. 26, pp. 265-291, 2021.

[15] D. M. Rousseau, "A sticky, leveraging, and scalable strategy for high-quality connections between organizational practice and science," Academy of Management Journal, vol. 50, no. 5, pp. 1037-1042, 2007.

[16] G. J. Greguras and J. M. Diefendorff, "Different fits satisfy different needs: linking person-environment fit to employee commitment and performance using self-determination theory," Journal of Applied Psychology, vol. 94, no. 2, p. 465, 2009.

[17] T. M. Amabile, R. Conti, H. Coon, J. Lazenby, and M. Herron, "Assessing the work environment for creativity," Academy of Management Journal, vol. 39, no. 5, pp. 1154-1184, 1996.

[18] N. Banerjee, E. Stearns, S. Moller, and R. A. Mickelson, "Teacher job satisfaction and student achievement: the roles of teacher professional community and teacher collaboration in schools," American Journal of Education, vol. 123, no. 2, 2017.

[19] X. Dumay and B. Galand, "The multilevel impact of transformational leadership on teacher commitment: cognitive and motivational pathways," British Educational Research Journal, vol. 38, no. 5, pp. 703-729, 2012.

[20] I. V. Allen, A. M. James, I. V. James Riddell, T. Rosenblat, D. Yang, and H. Yu, "Teaching and incentives: substitutes or complements?” National Bureau of Economic Research, vol. 35, 2021.

[21] D. Raufelder and S. Kulakow, "The role of the learning environment in adolescents' motivational development," Motivation and Emotion, vol. 45, no. 3, pp. 299-311, 2021.

[22] R. B. Briner, "Relationships between work environments, psychological environments and psychological well-being," Occupational Medicine, vol. 50, no. 5, pp. 299-303, 2000.

[23] H. Gultekin and E. Acar, "The intrinsic and extrinsic factors for teacher motivation," Revista de Cercetare şi Intervenţie Socială, vol. 47, 2014.

[24] D. Kember and D. Y. P. Leung, "Characterising a teaching and learning environment conducive to making demands on 
students while not making their workload excessive," Studies in Higher Education, vol. 31, no. 2, pp. 185-198, 2006.

[25] S. M. Johnson, M. A. Kraft, and J. P. Papay, "How context matters in high-need schools: the effects of teachers' working conditions on their professional satisfaction and their students' achievement," Teachers College Record, vol. 114, no. 10, pp. 1-39, 2012.

[26] M. A. Hassanain and I. Ali, "Framework model for postoccupancy evaluation of school facilities," Structural Survey, vol. 29, 2015.

[27] S. Sims, "Modelling the relationships between teacher working conditions, job satisfaction and workplace mobility," British Educational Research Journal, vol. 46, no. 2, pp. 301320, 2020.

[28] J. Sebastian, H. Huang, and E. Allensworth, "Examining integrated leadership systems in high schools: connecting principal and teacher leadership to organizational processes and student outcomes," School Effectiveness and School Improvement, vol. 28, no. 3, pp. 463-488, 2017.

[29] C. Day and Q. Gu, "Teacher emotions: well being and effectiveness," in Advances in Teacher Emotion Research, P. A. Schutz and M. Zembylas, Eds., Springer, Boston, MA, USA, 2009.

[30] C. Emslie and K. Hunt, "Live to work'or 'work to live'? A qualitative study of gender and work-life balance among men and women in mid-life," Gender, Work and Organization, vol. 16, no. 1, pp. 151-172, 2009.

[31] O. Amtu, K. Makulua, J. Matital, and C. M. Pattiruhu, "Improving student learning outcomes through school culture, work motivation and teacher performance," International Journal of Instruction, vol. 13, no. 4, pp. 885-902, 2020.

[32] Y. Liu, M. Ş. Bellibaş, and G. . Sedat, "The effect of instructional leadership and distributed leadership on teacher self-efficacy and job satisfaction: mediating roles of supportive school culture and teacher collaboration," Educational Management Administration \& Leadership, vol. 49, no. 3, pp. 430-453, 2021.

[33] F. F. Moore, The Role of Good Quality Student-Teacher Relationships when Working with Students with Challenging Behaviours in Mainstream Primary Schools in Western Australia, ECU, Australia, 2021.

[34] J. Håkansson and C.-H. Adolfsson, "Local education authority's quality management within a coupled school system: strategies, actions, and tensions," Journal of Educational Change, vol. 6, 2021.

[35] T. J. Kane, S. Eric, J. H. T. Taylor, and A. L. Wooten, "Evaluating teacher effectiveness: can classroom observations identify practices that raise achievement?" Education Next, vol. 11, no. 3, pp. 54-61, 2011.

[36] M. Azizi and M. Nemati, "Motivating the unmotivated: making teacher corrective feedback work," Issues in Language Teaching, vol. 7, no. 1, pp. 87-110, 2018.

[37] M. A. Adarkwah, "The power of assessment feedback in teaching and learning: a narrative review and synthesis of the literature," SN Social Sciences, vol. 1, no. 3, pp. 1-44, 2021.

[38] W. D. Rock, T. P. Remley, and L. M. Range, "Principalcounselor collaboration and school climate," NASSP Bulletin, vol. 101, no. 1, pp. 23-35, 2017.

[39] A. Balyer, "Trust in school principals: teachers' opinions," Journal of Education and Learning, vol. 6, no. 2, pp. 317-325, 2017.

[40] A. S. Bryk and B. L. Schneider, Trust in Schools: A Core Resource for Improvement, Russell Sage Foundation, New
York, NY, USA, 2002, http://public.ebookcentral.proquest. com/choice/publicfullrecord.aspx? $\mathrm{p}=4416774$.

[41] M. Sun, S. Loeb, and J. A. Grissom, "Building teacher teams: evidence of positive spillovers from more effective colleagues," Educational Evaluation and Policy Analysis, vol. 39, no. 1, pp. 104-125, 2017.

[42] A. Wolgast and N. Fischer, "You are not alone: colleague support and goal-oriented cooperation as resources to reduce teachers' stress," Social Psychology of Education, vol. 20, no. 1, pp. 97-114, 2017.

[43] M. Brown, R. Kathleen, and S. R. Wynn, "Finding, supporting, and keeping: the role of the principal in teacher retention issues," Leadership and Policy in Schools, vol. 8, no. 1, pp. 37-63, 2009.

[44] M. Sun, "Black teachers' retention and transfer patterns in North Carolina: how do patterns vary by teacher effectiveness, subject, and school conditions?" AERA Open, vol. 4, no. 3, Article ID 2332858418784914, 2018.

[45] M. Lee and K. S. Louis, "Mapping a strong school culture and linking it to sustainable school improvement," Teaching and Teacher Education, vol. 81, pp. 84-96, 2019.

[46] C. K. Jackson and B. Elias, "Teaching students and teaching each other: the importance of peer learning for teachers," American Economic Journal: Applied Economics, vol. 1, no. 4, pp. 85-108, 2009.

[47] M. Tschannen-Moran and C. R. Gareis, "“Faculty trust in the principal: an essential ingredient in high-performing schools." edited by heather E. Price and nienke M. Moolenaar," Journal of Educational Administration, vol. 53, no. 1, pp. 66-92, 2015.

[48] E. Kennedy, "Improving literacy achievement in a highpoverty school: empowering classroom teachers through professional development," Reading Research Quarterly, vol. 45, no. 4, pp. 384-387, 2010.

[49] D. Tattum, "Disruptive pupils: system rejects?" Pupil Experience, vol. 90-105, 2019.

[50] E. A. Hanushek, D. O. 'B. John Kain, and S. G. Rivkin, The Market for Teacher Quality, National Bureau of Economic Research, Cambridge, UK, 2005.

[51] C. S. Okoro, M. Nkambule, and A. Kruger, "The state of restroom facilities as a measure of cleaning service quality in an educational institution," Journal of Corporate Real Estate, vol. 23, no. 1, pp. 55-68, 2021.

[52] P. Benoliel, "Principals' boundary activities and school violence: the mediating role of school management teams," Educational Management Administration \& Leadership, vol. 48, no. 2, pp. 286-304, 2020.

[53] K. Shibuya, "Community participation in school management from the viewpoint of relational trust: a case from the akatsi south district, Ghana," International Journal of Educational Development, vol. 76, Article ID 102196, 2020.

[54] T. Saloviita and E. Pakarinen, "Teacher burnout explained: teacher-, student-, and organisation-level variables," Teaching and Teacher Education, vol. 97, Article ID 103221, 2021.

[55] G. Hanko, Special Needs in Ordinary Classrooms: From Staff Support to Staff Development, Routledge, England, UK, 2018.

[56] D. M. Patton, "Predictive relationships between school counselor role ambiguity, role diffusion, and job satisfaction," PhD Thesis, Walden University, Washington, DC, USA, 2019.

[57] Karasek Jr and A. Robert, "Job demands, job decision latitude, and mental strain: implications for job redesign," Administrative Science Quarterly, vol. 15, pp. 285-308, 1979.

[58] D. Jonge, H. B. Jan, R. Peter, and J. Siegrist, "Job strain, effortreward imbalance and employee well-being: a large-scale 
cross-sectional study," Social Science \& Medicine, vol. 50, no. 9, pp. 1317-1327, 2000.

[59] H. M. Weiss and C. Russell, "Affective events theory," Research in Organizational Behavior, vol. 18, no. 1, pp. 1-74, 1996.

[60] N. M. Ibrahim, M. M. Osman, S. Bachok, and M. Z. Mohamed, "Assessment on the condition of school facilities: case study of the selected public schools in gombak district," Procedia-Social and Behavioral Sciences, vol. 222, pp. 228-234, 2016.

[61] F. Herzberg, One More Time: How Do You Motivate Employees?, Harvard Business Review Press, Brighton, MA, USA, 2008.

[62] I. Oplatka, "Principal workload: components, determinants and coping strategies in an era of standardization and accountability," Journal of Educational Administration, vol. 5, 2017.

[63] P. D. Wiens, J. LoCasale-Crouch, A. Henry Cash, and F. R. Escudero, "Preservice teachers' skills to identify effective teaching interactions: does it relate to their ability to implement them?" Journal of Teacher Education, vol. 72, no. 2, pp. 180-194, 2021.

[64] R. M. Ingersol, "Teacher turnover and teacher shortages: an organizational analysis," American Educational Research Journal, vol. 38, no. 3, pp. 499-534, 2001.

[65] H. W. Marsh and H. Dennis, "Application of confirmatory factor Analysis to the study of self-concept: first-and higher order factor models and their invariance across groups," Psychological Bulletin, vol. 97, no. 3, p. 562, 1985.

[66] J. H. Steiger, "Structural model evaluation and modification: an interval estimation approach," Multivariate Behavioral Research, vol. 25, no. 2, pp. 173-180, 1990.

[67] E. E. Rigdon, "CFI versus RMSEA: a comparison of two fit indexes for structural equation modeling," Structural Equation Modeling: A Multidisciplinary Journal, vol. 3, no. 4, pp. 369-379, 1996.

[68] J. Deegan Jr, "On the occurrence of standardized regression coefficients greater than one," Educational and Psychological Measurement, vol. 38, no. 4, pp. 873-888, 1978.

[69] I. Berkovich and O. Eyal, "Transformational leadership, transactional leadership, and moral reasoning," Leadership and Policy in Schools, vol. 20, no. 2, pp. 131-148, 2021.

[70] M. T. Espuny, R. S. Cunha, I. Cabral, and J. M. Alves, "Giving voice to problems faced by school leaders in Portugal," School Leadership \& Management, vol. 40, no. 4, pp. 352-372, 2020.

[71] J. Maas, S. Simone, U. Scholz et al., “Teachers' perceived time pressure, emotional exhaustion and the role of social support from the school principal," Social Psychology of Education, vol. 24, no. 2, pp. 441-464, 2021.

[72] D. Goldhaber, "Everyone's doing it, but what does teacher testing tell us about teacher effectiveness?" Journal of Human Resources, vol. 42, no. 4, pp. 765-794, 2007.

[73] E. Daniëls, A. Hondeghem, and D. Filip, "A review on leadership and leadership development in educational settings," Educational Research Review, vol. 27, pp. 110-125, 2019.

[74] C. T. Clotfelter, H. F. Ladd, and J. L. Vigdor, "Teacher-student matching and the assessment of teacher effectiveness," Journal of Human Resources, vol. 41, no. 4, pp. 778-820, 2006.

[75] C. T. Clotfelter, "Teacher credentials and student achievement in high school a cross-subject analysis with student fixed effects," Journal of Human Resources, vol. 45, no. 3, pp. 655-681, 2010.
[76] R. M. Ingersoll and T. M. Smith, "The wrong solution to the teacher shortage," Educational Leadership, vol. 60, no. 8, pp. 30-33, 2003.

[77] T. Corcoran and M. Goertz, "Instructional capacity and high performance schools," Educational Researcher, vol. 24, no. 9, pp. 27-31, 1995.

[78] L. Darling-Hammond and G. Sykes, "Wanted, a national teacher supply policy for education: the right way to meet the" highly qualified teacher" challenge," Education Policy Analysis Archives, vol. 11, p. 33, 2003.

[79] U. Budi, M. Arita, D. Safitri, and A. Wahyudi, "Model of school management based on character building in school culture," International Journal of Advanced Science and Technology, vol. 29, no. 6, pp. 1161-1166, 2020.

[80] K. Haycock, "Good teaching matters: how well-qualified teachers can close the gap," Thinking K-, vol. 163, no. 2, p. n2, 1998.

[81] L. Darling-Hammond, "Keeping good teachers: why it matters, what leaders can do," Educational Leadership, vol. 60, no. 8, pp. 6-13, 2003.

[82] B. Olsen and D. Sexton, "Threat rigidity, school reform, and how teachers view their work inside current education policy contexts," American Educational Research Journal, vol. 46, no. 1, pp. 9-44, 2009.

[83] K. J. Debnam, K. Edwards, and D. Cornell, "Improving the school environment: school staff perceptions of school climate data and reporting practices," Journal of Community Psychology, vol. 49, no. 6, pp. 1965-1982, 2021.

[84] W. Fikuree, F. Meyer, D. Le Fevre, and M. Alansari, "Linking principal task effectiveness to student achievement in secondary schools in the Maldives," International Journal of Leadership in Education, vol. 1-18, 2021.

[85] A. Protik, S. Glazerman, and J. Bruch, "Staffing a low-performing school: behavioral responses to selective teacher transfer incentives," Education Finance and Policy, vol. 10, no. 4, pp. 573-610, 2015. 